University of Nebraska - Lincoln

DigitalCommons@University of Nebraska - Lincoln

To Improve the Academy

Professional and Organizational Development Network in Higher Education

1994

\title{
Academic Leaders and Faculty Developers: Creating an Institutional Culture That Values Teaching
}

Norman D. Aitken

Mary Deane Sorcinelli

Follow this and additional works at: https://digitalcommons.unl.edu/podimproveacad

Part of the Higher Education Administration Commons

Aitken, Norman D. and Sorcinelli, Mary Deane, "Academic Leaders and Faculty Developers: Creating an Institutional Culture That Values Teaching" (1994). To Improve the Academy. 300.

https://digitalcommons.unl.edu/podimproveacad/300

This Article is brought to you for free and open access by the Professional and Organizational Development Network in Higher Education at DigitalCommons@University of Nebraska - Lincoln. It has been accepted for inclusion in To Improve the Academy by an authorized administrator of DigitalCommons@University of Nebraska - Lincoln. 


\section{Academic Leaders and Faculty Developers: Creating an Institutional Culture That Values Teaching}

\section{Norman D. Aitken}

\section{Mary Deane Sorcinelli}

University of Massachusetts Amherst

In recent years, a great deal has been said and written about the need to improve teaching in the academy, especially in large research universities. College presidents, national associations representing higher education, private foundations, and individual faculty scholars all have challenged faculty, chairs, deans, campus administrators, and faculty developers to work together to improve support for undergraduate teaching and learning (Bok, 1986; Bowen \& Schuster, 1986; Boyer, 1987; Carnegie Foundation for the Advancement of Teaching, 1989; Diamond \& Adam, 1993; Seldin \& Associates, 1990). Despite such calls for collaborative efforts to improve undergraduate education, faculty developers still often feel alone in a milieu that does not value teaching and frequently perceive a lack of support from academic leaders, particularly the central administration. Administrators, on the other hand, often recognize the need to improve institutional support for teaching, but are at a loss as to how to effectively intervene to change the environment. 
As a deputy provost and a director of a center for teaching, we have worked collaboratively over the past six years to achieve a common goal: to encourage a culture on campus that values teaching. While we would like to take credit for carefully planning all of the strategies that evolved as a result of our cooperative ventures, the truth is that most of them emerged as each moment of opportunity presented itself. In retrospect, however, we can identify some of the key strategies that have proven to be the catalysts for our institution's renewal in teaching. In this case study, we will describe the kinds of programs we've developed, identify some of the key strategies, summarize what we've learned throughout these six years, and describe the impact our efforts have had on our institution's commitment to excellence in teaching. We hope that some of what worked well for us can be applied by campus administrators and faculty developers on other campuses.

\section{Institutional Context}

The University of Massachusetts Amherst is the oldest and largest of the five University of Massachusetts campuses, enrolling over 23,000 students in a full spectrum of undergraduate, graduate, and professional programs. The campus characterizes itself, and is nationally ranked by Carnegie Classification as a Research I University. Its faculty are recipients of an array of prestigious honors and awards in research, and the University actively supports several resource agencies, including an Office of Research Affairs and a campus-wide Institute For Advanced Studies.

Over the last decade or so, while there was a quiet affirmation of high-quality teaching at the University, there were few special programs offered to assist faculty in this area. The campus's nationally recognized Clinic To Improve University Teaching and Center for Instructional Research and Improvement (CIRI) were established in the early 1970s and then closed during the budget cuts later in that decade. After 1978, there was only one agency left to assist instructors in teaching - the Audio-Visual Department.

During the mid 1980s, a series of events provided the springboard for renewed interest in teaching. As part of its accreditation review, 
the University conducted a self-study which called for more attention to teaching and learning. The Provost also appointed a new vice chancellor for academic affairs (who was later named deputy provost) and asked him to look at a constellation of issues related to undergraduate education. At the same time, the University was invited to submit a proposal for a Lilly Teaching Fellows Award Program to introduce untenured faculty to the profession of teaching. The combination of events could not have been better timed, and together they provided the stimulus for improving the climate for teaching.

\section{Initiatives in Teaching and Learning}

Between 1986 and 1994, we developed and refined a series of programs in ways that have allowed them to become embedded in the culture of the University. They included establishing a teaching fellows program, a "celebration of teaching" dinner, a center for teaching development, an annual teaching assistant orientation, and deans and chairs conference. In this section we will briefly describe each of those key programs as it developed, in chronological time.

Faculty Teaching Fellowships, Fall 1986. The teaching fellows program was funded for the first three years of its existence by the Lilly Endowment, but has been funded by the University for the last five years. It has also increased its scope by including not only tenure track junior faculty, but also faculty who have been awarded tenure in the previous three years. Teaching fellows do not receive any direct compensation but are provided with release time from their teaching, usually $50 \%$ of their total teaching commitment for an academic year, to participate in program activities. Fellows attend a biweekly "seminar on college teaching," work on a project for their home academic department (usually the development of a new course or the revision of an existing course), engage in an individual consultation process (e.g., class visits, videotaping, student feedback), and work with a senior faculty mentor.

Celebration of Teaching Dinner, Spring 1987. The annual Celebration of Teaching Dinner provides an occasion at which members of the University community across disciplines, departments, and ranks come together to publicly acknowledge and celebrate the im- 
portance of teaching. It is not an award program, but rather an event where faculty come to hear other faculty talk about their teaching. The most popular part of the program is the Teaching Fellows presentations, which deal either with memorable experiences faculty have had during their fellowship year or in their teaching career. The dinner consistently draws an audience of some 250 faculty and staff and has always had the provost or chancellor in attendance. Faculty from the departments of the teaching fellows are invited and usually attend in significant numbers. The dinner is also well attended by previous faculty teaching fellows, as well as Distinguished Teaching Award winners, winners of the Chancellor's Medal for outstanding research contributions, and deans, department heads, and chairs.

Center For Teaching, Fall 1988. The success of the teaching fellowship program and the associated celebration of teaching dinner enabled the University to assemble critical support among faculty in order to establish a Center For Teaching. The Center was approved by the University's Faculty Senate and opened in the Fall semester 1988. Since its inception, the Center has offered an ever-increasing range of resources and programs for enhancing teaching and learning. They include individual consultations, departmental consultations, workshops, seminars, conferences, teaching assistant training programs, annual award programs such as the Teaching Fellows Program and Faculty Grants For Teaching, materials on teaching development, and institutional participation in grants and research on teaching and faculty development.

Campus-Wide Teaching Assistant Orientation, Fall 1989. This day-long orientation is offered by the Center under the sponsorship of the Provost's Office and Graduate School. The agenda includes a panel of experienced TAs who share their perspective and advice on becoming a teaching assistant, department representatives who lead a departmental luncheon, and faculty who lead workshops on such topics as leading discussions, social and cultural diversity in the classroom, and critical moments in college teaching. A unique aspect of the program is the requirement of departmental commitment as a requisite to involvement in the orientation. Department chairs appoint a faculty liaison to our Center and, working in coordination with us, invite TAs to the program and participate in a departmental luncheon. 
In this way, not only TAs but also the department chair and faculty representatives are invested in the orientation.

Deans and Chairs Conference, Fall 1991. As part of a FIPSE funded Focus on Teaching Project (Diamond \& Adam, 1993), the campus initiated a day-long campus conference to enable all chairs, deans, and academic administrators to discuss the role of academic leaders in supporting undergraduate teaching and learning. A committee of chairs, deans, and administrators plans the conference, which is now an annual event, and over $80 \%$ of academic leaders, including the Provost and Chancellor, have attended each year. Conference themes have included Teaching and Research, Creating a Multicultural Campus, and The Changing University.

\section{Strategies for Developing a Teaching Culture}

How can we tell that these five initiatives have become institutional features? In retrospect we can see we took some crucial steps that assured the lasting effect of these programs on the culture for teaching at the University. In this section we will discuss five basic strategies that contributed to the longevity and success of our initiatives and provide examples of how these strategies are embodied, in one form or another, in our programs.

These strategies are now incorporated into all our planning because they have proven so successful in helping a teaching community to flourish. As the program descriptions and the accounts of strategies both reveal, there is a great deal of overlap among the five principles we have come to depend upon. And in a way, that is the point: linkages are the linchpin of effective and long-lasting efforts to integrate a teaching culture into the life of the University.

Identify Existing Support for Teaching. On any campus there are a number of faculty and administrators who have a strong commitment to teaching. Frequently, these individuals have not been identified, nor have they been provided with a forum in which they can express their support for teaching and meet colleagues with similar views. Engaging these individuals, then, is a solid first step in building community and in identifying excellence in teaching as an indwelling asset on campus, rather than as something to be imported or enforced. 
The Teaching Fellows Program served as the first catalyst in this process. Early on we felt that the program would be successful if it was perceived as prestigious. Because the program was designed as a competitive fellowship offering release time, department chairs nominated promising young teachers and researchers to work with us. The junior faculty, in turn, selected mentors. This is when we realized that there were senior faculty who had been seeking a forum for sharing their commitment to teaching with others. When the program was initiated in the Fall of 1986, a retreat was held which brought together six distinguished senior faculty (mentors) with six energetic and enthusiastic junior faculty. At that retreat there was a revealing moment when after an extensive discussion of teaching, a mentor who is a highly distinguished scholar said "In all the years I have been at this university, I have been asked to speak about my research numerous times, but this is the first time I have ever been asked to talk about teaching."

Dedicated faculty such as these helped to establish the credibility of the program campus wide. The notion of seeking support from key faculty members was reinforced as we worked to create a campuswide teaching center. Teaching development centers need to be identified with and work closely with outstanding faculty. Directors of centers might look at the model of a research institute which brings together the very best research faculty as a way of encouraging scholarship in particular areas. They should avoid the image of such centers being the place where teachers are "sentenced" to go to improve their teaching skills. While faculty who need help in their teaching should be welcomed and supported, teaching centers also need to bring together the very best teachers on campus for the purpose of improving teaching for all faculty and should use outstanding faculty to provide programming and new experiments to improve teaching.

In short, support for teaching involves not only providing the resources to enable teachers to improve but also showcasing the real accomplishments and talents of instructors who are "local experts." In this way, a teaching center comes to be seen not only as a source of help but also as the hub of intellectual and creative activity related to teaching. 
Build Support at Multiple Levels. A recent study of attitudes toward teaching on college and university campuses (Grey, Froh, \& Diamond, 1992), funded by the Fund for the Improvement of PostSecondary Education (FIPSE), asked academic administrators, deans, department chairs, and faculty members on over 100 campuses not only to provide their views on what the appropriate balance between teaching and research should be but also to rate the values of other participants in the study (e.g., individual faculty provided their own view on the appropriate balance between research and teaching and also noted what they thought were the values of their department chair, dean, and central administrators). One of the most fascinating conclusions of the study was that faculty generally saw themselves as valuing teaching more highly than their department chair, dean, or the central administration; department chairs and deans saw themselves as valuing teaching more highly than the central administration; and central administrators saw themselves as valuing teaching more highly than deans and department heads. In other words, there is a considerable amount of latent support for teaching among faculty and academic leaders at all levels; thus, there are opportunities to create a more supportive environment for teaching at most institutions. To be effective, however, interventions need to take place at all levels.

Central Administration. The central administration frequently understands the need to improve teaching on the campus in terms of external constituencies (from parents, alumni, trustees, and legislators) but just as frequently believes that there is little support on campus for teaching and may be reluctant to take a stand on the issue for fear that they will be perceived as not supporting the research mission of the institution. In this situation, the faculty developer can be very effective in obtaining central administration support for teaching development efforts by identifying - for the central administration - a critical mass of faculty who support teaching development, including faculty of high stature within the institution who are apt to be perceived as leaders by their colleagues.

Our first Celebration of Teaching Dinner was a breakthrough in terms of providing the central administration with evidence that there was wide-spread support for good teaching and a desire to recognize it. The provost (who was later appointed chancellor) attended. When 
he saw the size and composition of the audience, and observed the response to the event, he became convinced that there was a large community of faculty who supported teaching. And, over the last eight years, he has returned to and participated in every celebration dinner. More importantly, when the three-year Lilly Endowment grant ended, the provost decided to fully fund out of his office the teaching fellows program. The internal funds have been protected for six years now, despite the fact that in recent years the provost's area and all of academic affairs have been particularly hard hit by budget cuts.

The teaching center, which houses the teaching fellows, also helps to foster central administrative support for teaching. It provides contact between fellows and central administrators, which enables the fellows to talk about their experiences and demonstrates to administrators that there are exceptional junior faculty on campus who are committed to teaching. In addition, the Center works with the central administration to provide campus-wide conferences and retreats. In its structure and programs, the Center itself models the strategy of continually building multilevel support for its efforts.

Deans and Department Chairs. Many deans and department chairs would like a more supportive environment for teaching but feel that their efforts would not be supported by either the central administration or by individual faculty members in their department or college. In order to improve support at this level within the institution, department heads indeed need to be convinced that both the central administration and the faculty at large support teaching. Since this requires support from both above and below, the so-called "middle management" of the university is one of the most difficult to move in the direction of supporting teaching at a research institution.

We began to court chairpersons by enlisting their support in the Teaching Fellows Program. We emphasized that candidates must be nominated by their department chairs because we were convinced that without a supportive climate within the department it would be difficult for the fellow to sustain newly learned views and skills in teaching. We also stressed the ability of the program to provide recognition to the home academic department and to reward the department with curriculum development opportunities. As fellows developed teaching skills in a interdisciplinary and collaborative environment, chairs 
began to see that at the end of the year the department received back a faculty member who was now a trained teacher who could share ideas with other faculty within and beyond the department.

Further connections with academic departments were created by the teaching center over time. For example, we now design departmental workshops and consultations on specific topics requested by various departments. We also ask for departmental commitment to an interdisciplinary teaching assistant orientation in which both TAs and faculty representatives of each department are involved, and publish a teaching handbook that is available free of charge to TAs and faculty in all departments.

The deans and chairs conference provides another opportunity to address the need for support for teaching from this stratum of academic leadership. Department heads and chairs are critical in changing the teaching culture on campus, but there are few early intervention strategies that allowed us to work directly with this critical group of individuals. Being invited to participate in the FIPSE Focus on Teaching Project provided the provost's office and the teaching center with a timely opportunity to work with the department chairs and heads on campus. The first conference tackled the issue of the balance between teaching and research. That day-long conference began with presentations by the chancellor and provost followed by opportunities for the chairs to meet in small groups across disciplines to discuss issues raised in the large group sessions. At the end of the day, the chairs and heads were assembled by college with their deans and asked to develop strategies for better balancing teaching and research. The conference encouraged participants to describe the initiatives that they had successfully introduced to support teaching and to discuss opportunities for future policies and programs.

Individual Faculty. To improve faculty support for teaching, individual faculty members must be convinced that there are a significant number of other faculty on campus that support teaching and that the administration, at all levels, values teaching, especially at the undergraduate level.

The Teaching Fellows Program reached out to selected junior faculty and their mentors, but the base of support and involvement needed broadening. This was accomplished in several ways, through 
largely through programs housed at the Center For Teaching. In order to involve faculty across academic ranks, disciplines, and career stages, the center offered an array of teaching improvement opportunities. For example, well-publicized campus-wide workshops, such as those on academic honesty in the classroom and writing as a tool to help students learn, were aimed at a wide range of needs. These workshops helped to bring together and make visible the cohort of dedicated teachers, both as audience members and as presenters. In addition, Center staff provided both comprehensive and short-term consultation services, midterm course evaluations, print and video resources, a newsletter, and small grants for implementing innovative teaching materials or techniques.

In sum, since the support for teaching that exists at each level of the university depends in part on the support from other levels of the university, the faculty developer will be successful in improving faculty teaching to the extent that she has been able to garner support for teaching within the central and departmental administrations. The converse is also true: that obtaining support by administrative units is more easily accomplished if the campus already has broad-based faculty support for teaching. Our programs have usually been directed at more than one of the three levels but have sometimes emphasized one or the other - central administrators, deans, department chairs, or faculty-depending on the circumstances at hand.

Create Community and Collegiality Around Teaching. Despite being attracted to the autonomy offered by an academic career, faculty still desire support from each other. Most faculty we've worked with have expressed a sincere longing to talk about teaching with colleagues both within and outside their disciplines, departments, and colleges. Over the years, we've put increased effort into figuring out ways to bring individuals - not only faculty, but also chairs, deans, and campus administrators - together. Whether through peer visits, informal study groups, conferences, or social events, the input of others offers new and original ideas, provides intellectual stimulation around teaching issues, and creates a sense of community that helps to break down the isolation felt by many college teachers.

In the Teaching Fellows Program, for example, collegiality is encouraged by selecting on interdisciplinary group of fellows, having 
the fellows meet regularly to talk about their teaching, and involving them in the design of the teaching development workshops series for the fellowship year, some of which will be available to the broader campus community.

The Center For Teaching fosters community by enlisting outstanding senior faculty to act as presenters in campus-wide workshops, to sit on University committees related to teaching, and to serve as "faculty associates" at the Center each year, where they are responsible for offering workshops and consultations to their colleagues. One of the Center's foremost aims is to provide, often in concert with other departments or campus agencies, a variety of programs over time to serve all disciplinary interests on campus, from the sciences to the arts, as well as program topics of general interest to the community as a whole, such as teaching in the diverse classroom, writing across the curriculum, and effectively teaching large classes. In addition, the Center and the provost's office attempt to respond to needs and create linkages both within and among individuals, departments, and colleges through such annual events as the Teaching Assistant Orientation, the Deans and Chairs Conference, and the Celebration of Teaching Dinner.

Seek Links with the Research Mission. Improving the teaching culture at research universities can be most effectively accomplished if development efforts do not come into conflict with the research culture of the institution. Both administrators and faculty are usually committed to the unique research capabilities of such an institution and should not be asked to choose between research and teaching. In fact, we recognized early on that many faculty believe that both teaching and research are important responsibilities; these individuals who have successfully united the two roles will be critical in improving the teaching climate on campus.

Their support can only be obtained, however, if the teaching development effort is perceived as being integrated with the research mission rather than in competition with it. We have addressed this in several ways. The mentors and fellows in the Teaching Fellows Program are not only committed teachers - many are also among the very best researchers in the institution. A subtle but very powerful link with the research mission is provided by giving the fellows release 
time (as opposed to other compensation) in order to participate in the fellowship year. This not only allows the fellows to participate in teaching development, but also gives them additional time to work on research. In addition, a notion of a "fellowship" is one both junior faculty and chairs resonate to as a vehicle for positively impacting a career.

While the Center For Teaching has tried to speak to the distinct concerns of faculty interested in teaching, it also has tried to transcend the artificial dichotomies between research and teaching. Because the Center has always sought the support of distinguished research faculty who are committed to teaching, it has not been viewed as a threat to the research mission and is valued throughout the campus community for its professional expertise, commitment to quality, and broad-based support for faculty development.

The topics of the annual deans and chairs conferences have also explored the relationship between teaching and research, as have a number of campus-wide workshops, such as those on teachers as writers, student learning styles, and models of racial identity in the classroom.

Provide Recognition and Reward. The motivation for good teaching is primarily intrinsic. Still, when we ask faculty for ideas on improving the climate for teaching, they often mention something vaguely described as a need for rewards. The need is in part salary or resources but is also clearly for more than that. It is difficult for research universities to balance rewards between "stars" and the wider group of "good citizens" who teach undergraduates, sit on committees, and the like. We make a conscious effort to take notice of all efforts to improve teaching, whether by individual faculty or departments or colleges within the institution, and to give them as much publicity as possible. Such efforts include not only distinguished teaching awards, but also opportunities for faculty and academic leaders to present their ideas and programs on teaching.

The Teaching Fellows Program provides extensive recognition of the junior faculty selected as fellows and the senior faculty who serve as mentors. The program also distinguishes the departments and colleges from which the faculty fellows are selected. Recognition is provided through the Celebration of Teaching Dinner, newspaper 
publicity, and opportunities for the fellows to meet with both the chancellor and the provost during their fellowship year.

In addition, the Center For Teaching tries to take note of the achievements of faculty members and congratulate them on a smaller scale. For example, our weekly newspaper, the Campus Chronicle, often reports faculty contributions both within and outside the institution. We respond to as many of these reports as possible. As a result, any "faculty friend of the Center" who has developed a new course, completed a textbook or scholarly project, received tenure or promotion, or provided conscientious service on a teaching-related committee receives a note from us. Admittedly, this activity is time consuming, but it is exceedingly low cost and high yield in terms of faculty appreciation.

For explanatory purposes we have dissected our programs and strategies. In reality, however, they are always multifaceted in both design and execution. One example of this interwoven quality is the celebration of teaching dinner. The dinner not only honors the fellows and mentors who have participated in the teaching fellows program but also brings together the larger campus community which is committed to teaching for a festive evening that is solely and unashamedly about teaching and learning. The notions of providing multilevel support, collegiality, linkage with the research mission, and ample measures of appreciation are fostered by the simple strategy of inviting representatives from all constituencies of the campus, including academic leaders, faculty who have been recognized by the campus as either outstanding teachers and/or outstanding scholars, academic staff, and students.

In may seem ironic that the subtlest blend of the five strategies is to be found in a social rather than a strictly academic event. However, university life can be fragmented by disciplinary allegiances, scholarly activities, campus politics, and financial hardship. This single event crosses all those boundaries to affirm that teaching, and the relationships which cause it to thrive, transcends the concerns that can divide us into competing camps within the same institution. 


\section{The Future}

Two new initiatives are currently being undertaken. As a result of a campus commitment to improving faculty and teaching assistant training, especially for teaching in the diverse classroom, the Center For Teaching has been awarded funding from the President's Office to develop a faculty and TA development program around issues of diversity. The program is being planned with many of the aforementioned strategies in mind. In particular, the program will extend the linkages we've already developed with departments by working across units to provide campus-wide resources for teaching, learning, and diversity, as well as customized diversity training for each department or cluster of departments.

The second initiative deals with the critical issue of faculty roles and rewards. As part of a strategic planning process, a committee on faculty roles and rewards has been established by the chancellor. It is too early to tell what the outcomes of this effort will be, but the goal is to provide a fair and just system of rewards compatible with the roles for which faculty are responsible. We hope to achieve a campuswide consensus concerning the rewards for teaching and research and to eventually develope a reward structure which will ensure that both activities are encouraged and rewarded fairly.

Much of what we've discovered about creating an institutional culture that values teaching can be found in the prime importance of: identifying support of all kinds, crossing boundaries and creating linkages of all kinds, providing all kinds of opportunities for collegiality, and providing all kinds of ways for faculty to develop and receive recognition as teachers. If one were seeking strategies for creating a teaching culture on any campus, these strategies might be places to begin.

\section{References}

Bok, D. (1986). Higher learning. Cambridge, MA: Harvard University Press.

Bowen, H.R., \& Schuster, J.H. (1986). American professors: A national resource imperiled. New York: Oxford University Press.

Boyer, E.R. (1987). College: The undergraduate experience in America. New York: Harper \& Row. 
Carnegie Foundation For The Advancement of Teaching. (1989). Condition of the professoriate (Technical Report). Washington DC: Carnegie Foundation for the Advancement of Teaching.

Diamond, R.M., \& Adam, B.E. (1993). Recognizing faculty work: Reward systems for the year 2000. New Directions in Teaching and Learning, No. 80. San Francisco: Jossey-Bass.

Gray, P.J., Froh, R.C., \& Diamond, R.M. (1992). A national study of research universities on the balance between research and undergraduate teaching. Syracuse, NY: Center for Instructional Development, Syracuse University.

Seldin, P., \& Associates. (1990). How administrators can improve teaching. San Francisco: Jossey-Bass. 